\title{
Paradoxos societais e juventude contemporânea
}

\author{
Norma Missae Takeuti \\ Universidade Federal do Rio Grande do Norte
}

\begin{abstract}
Resumo
Com foco nos jovens da América Latina, discutem-se os paradoxos societais que incidem fortemente sobre eles na atualidade. Um dos paradoxos importantes diz respeito, de um lado, à transformação contemporânea das significações sociais da juventude, nas quais o ser jovem passa a ser uma referência central para todas as faixas etárias e, de outro, às limitações da realidade concreta e objetiva que reduz o campo de possibilidades de realização dos jovens na vida profissional e social. Associado a isso, vê-se o desenvolvimento de um processo discursivo na sociedade atual, que revela a vontade de punir os jovens. Vontade associada a dois movimentos articulados entre si: a passagem do Estado-Providência para o Estado Penal; a política global da sociedade de controle. Como desdobramento desses processos, evidencia-se o paradoxo do poder e da multiplicidade - controles e resistências. Ao final, enfatiza as experimentações sociais positivas de determinados grupos de jovens na atualidade.
\end{abstract}

Palavras-chaves: juventude e paradoxos societais; vontade de punir; sociedade de controle; resistências; experimentações sociais.

\begin{abstract}
Societal paradoxes and contemporary youth. This article focuses on young people in Latin America. It discusses the societal paradoxes reflecting heavily on them today. An important paradox concerns on one hand, to the contemporary changes of the social meanings of being youth stands as a central reference of excellence to the entire society and, on the other, the limitation of objective and concrete reality which reduces the range of possibilities for realization in professional and social life. Associated with this, the development of a discursive process in today's society that reveals the will to punish the youth is also analyzed. This analysis is connected with two articulated processes: the transition from Welfare State to the Penal State; the overall policy of the society of control. The paradox of power and multiplicity - controls and resistances are the consequence of these processes. Finally, the article emphasizes the positive social experimentations of certain groups of young people today.
\end{abstract}

Keywords: youth and societal paradoxes; will to punish; society of control, resistance and social experimentations.

\section{O campo do conhecimento sobre a juventude}

Para discutir o tema proposto neste Simpósio ${ }^{1}$ - Juventudes da América Latina -, faremos um necessário recorte temático. Nossa opção recai sobre a discussão de alguns aspectos paradoxais da sociedade contemporânea que incidem fortemente sobre a categoria juventude. Antes, contudo, faremos algumas considerações preliminares, para situarmos a nossa reflexão.

Inicialmente, temos por premissa que o tema juventude não pode ser abordado de modo universal. Menos ainda, quando delimitados a um espaço circunscrito social e geograficamente - a América Latina. A definição do ser jovem e a concepção das relações juvenis na complexa contemporaneidade estão atreladas aos contextos de ordem cultural, social, político e econômico de cada sociedade.

O que é ser jovem na atualidade latino-americana é um assunto bastante presente, através de pesquisas desenvolvidas, principalmente nesta última década ${ }^{2}$. Nunca, na América Latina, se discursou tanto sobre infância, adolescência e juventude como agora, desde a década de 1990. Antes disso, a própria literatura acadêmica era escassa e, no interior da própria sociologia da juventude, havia uma abordagem bastante restrita e circunscrita em alguns poucos campos problemáticos. Atualmente, essa fatia populacional tem sido alvo intensivo de práticas e processos discursivos (tal noção pensada a partir de Foucault; 1977; 1995; 2006a) nas sociedades latino-americanas. Têm-se, de um lado, estudos quantitativos na forma de grandes enquetes e surveys produzidas por organizações nacionais e internacionais ${ }^{3}$, e que têm por foco informações sistematizadas sobre quem são os jovens latino-americanos; sua amplitude e diversidade; semelhanças e diferenças; formas de sua organização; construção de estratégias para inserção em suas sociedades. Por outro, há estudos que combinam métodos quantitativos e qualitativos, com recurso a grupos focais compostos de pesquisadores e jovens.

Na biblioteca do Instituto Brasileiro de Análises Sociais e Econômicas (IBASE) estão disponibilizados vinte e três relatórios e livros no tema juventude, resultados de pesquisas realizadas, desde 2004, no continente sul americano. As publicações, sob a responsabilidade do IBASE e Instituto Pólis, com o apoio 
do Centro de Investigaciones para el Desarrollo Internacional (IDRC), abarcam o período de 2006 a 2010. Também, sob a organização de Novaes e Ribeiro, publicou-se em 2010, o Livro das Juventudes Sul-americanas, resultante de um projeto que congrega seis países sul americanos ${ }^{4}$. Há outras inúmeras pesquisas desenvolvidas e em curso no Brasil ${ }^{5}$ e na América Latina, com diversificadas abordagens para tratar de uma juventude que ganhou novas conformações sociais na atualidade.

Não só proliferam estudos e pesquisas nos meios acadêmicos e científicos como também fora deles, e quantitativamente há, cada vez mais, uma crescente intervenção junto à população infanto-juvenil, através das organizações governamentais e das organizações da sociedade civil, contribuindo para gerar uma abundante informação, em múltiplos recortes e finalidades. Imbuídos dos princípios da racionalidade instrumental de integração de jovens na sociedade, via estudos, capacitação técnica e trabalho, empreendem-se pesquisas e ações sociais na expectativa que delas derivem informações e efeitos concretos relativamente à "boa integração" dos jovens na sociedade, do mesmo modo que se esperam resultados concretos no plano de sua vida quotidiana. Em se tratando do Brasil, pode-se acrescentar, ainda mais agora, que da economia brasileira espera-se projeções para patamares privilegiados da economia mundial, precisa-se de jovens ativos e integrados econômica e profissionalmente. Nessa ambiência eufórica, visam-se também segmentos sociais onde se acumulou grande contingente de jovens - com baixo capital econômico, social, cultural e simbólico - que precisa ser absorvido com resultados imediatos. Não esqueçamos que esse potencial econômico brasileiro, ainda, não salvaguarda 60 milhões de pessoas em situação de pobreza que se debatem em meio às relações de desigualdade econômica, social e cultural.

Nessa profusão de saberes e experimentos sociais diversos junto à população infanto-juvenil, também despontam indagações sobre o efetivo avanço na problematização e compreensão do ser jovem confrontado com os diversos embates resultantes de paradoxos societais que, cada vez mais, se aprofundam. Pesquisas de cunho qualitativo poderiam, sem dúvida, contribuir no avanço dessa compreensão. Assim como discutiremos em seguida, é nesse ponto que nosso interesse de pesquisa se situa, lá onde há um apelo à dimensão subjetiva concernente aos jovens de hoje, isto é, a indagação da pesquisa recai sobre como eles estão lidando ou podendo lidar com os problemas inéditos que emergem na sociedade e lhes atingem intensamente. Preocupar-se com o processo de subjetivação juvenil é, igualmente, colocar questões sobre o devir jovem, sobre a condição de possibilidade dos jovens inventarem novos modos de existência; neste ponto, inspiramo-nos na genealogia do sujeito de Michel Foucault (1984, 2001, 2006b) e na noção de devir em Deleuze (1992a) e em Deleuze e Guattari (1997a, 1997b). E assim, discutir como eles possam assumir novos riscos e, em decorrência, pensar individual e coletivamente saídas para os bloqueios que se lhes interpõem em vários níveis. E quando pensamos em jovens que se debatem em meio às dificuldades materiais, na pobreza, perguntamo-nos se eles podem tentar, desde já, esboçar outra maneira de viver, não mais subsumida inteiramente nas violências sociais, mesmo diante da implacável realidade da permanência das desigualdades sociais. É muito provável que esses jovens enfrentem os paradoxos societais com maior impacto do que aqueles que podem contar efetivamente com suportes institucionais e familiares.

\section{Significação imaginária social da juventude e para- doxos}

O que intitulamos por paradoxos societais são processos que incidem sobre os indivíduos sociais imersos numa sociedade hiperconsumista, se pensarmos com Lipovetsky (2010), e mais diretamente sobre a juventude contemporânea, independentemente de sua pertença socioeconômica, quer seja dos países desenvolvidos (em grave crise atualmente, diga-se de passagem), quer seja dos ditos países em desenvolvimento ou países emergentes, como é o caso do Brasil. A América Latina, de um modo geral, é centro de atenções, por parte de analistas internacionais que ousam formular a ideia da "década latino-americana", conforme se cogitava na sexta edição do Fórum Econômico Mundial da América Latina 2011. Aí surgiam projeções de cenários positivos: apesar de estar a América Latina dentre as mais desiguais do mundo, ela apresentaria hoje potencialidades para se tornar uma economia forte no plano mundial.

Interessa nisso, observar que os jovens latino-americanos estão mergulhados nos paradoxos e dilemas que a sociedade contemporânea desenvolve sem cessar, do mesmo modo que os jovens de países que estiveram, até recentemente, encabeçando o quadro de desenvolvimento econômico, ao nível global. Resumidamente, a definição de "crise" relacionada aos jovens pode ser captada da seguinte maneira: se, de um lado, nos países desenvolvidos há o esgotamento das formas de trabalho impedindo a absorção de um contingente bem qualificado de jovens, cujas condições de vida são cada vez mais precarizadas; de outro, nos países de economia emergente (com projeções de menor crescimento em 2012 e 2013), há escassez de mão de obra qualificada para ocupar os postos de trabalho cada vez mais exigentes, tecnicizados e organizados pelos princípios produtivista e concorrencial. Destaquemos o essencial dessa discussão: para alçar maiores voos ou para não despencar em queda bruta, os jovens estão enfrentando alguns paradoxos que as sociedades contemporâneas lhes colocam.

Relembremos que, há mais de duas décadas, estamos vivendo um processo acelerado de transformações substanciais, a partir dos novos rumos da economia e em face das novas tecnologias comunicacionais, que vieram afetar vários domínios da vida humana e com sérias consequências nas relações dos indivíduos nos espaços sociais diversos - família, trabalho, instituição escolar, política, cultura e lazer. O modo de produção capitalista contemporâneo cria desafios inesperados nesses diversos espaços. Interessa-nos filtrar disso tudo o que há de paradoxo a partir das diversas contradições e tensões sociais, geradas nessas mutações, e que fazem com que os jovens se vejam com eles confrontados no seu processo de subjetivação, e num plano bem objetivo de produção de sua trajetória profissional e social na vida adulta. A esse respeito, Novaes e Santoro (2008) constatam, a partir dos artigos que compõem a coletânea Ser Joven en Sudamérica, que “jovens desta geração estariam mergulhados nas contradições da sociedade, sua 
condição juvenil é, em grande parte, constituída pelas grandes desigualdades e contradições que a atravessam" (p. 184, nota de rodapé). Concluem que, atualmente, os jovens "experimentam com maior intensidade os dilemas das sociedades onde vivem", de modo a se ver o "mundo da juventude como espaço de intensificação/agudização de contradições sociais.” (p.184-5).

Um dos paradoxos com os quais se confrontam os jovens na atualidade diz respeito, de um lado, à transformação contemporânea das significações sociais da juventude que os eleva ao patamar de excelência na inteligência, beleza, liberdade e sensualidade e, de outro, às limitações da realidade concreta e objetiva, onde o campo de possibilidades se acha bastante reduzido para a efetiva realização do jovem na vida profissional e social. Haveria uma incompatibilidade entre a ordem da representação e a ordem da realidade no campo da juventude, fazendo com que se produzam ideias e atitudes ambivalentes em relação ao jovem.

Concomitantemente, na sociedade contemporânea há uma produção imaginária exacerbada do ser jovem, sustentada pela indústria cultural que elege os jovens como sendo a fatia privilegiada do mercado consumidor. Isso tem como consequência a ampliação do campo de identificações imaginárias, onde a ideia de juventude passa a ser o "modelo social" para um amplo espectro de faixas etárias. Por exemplo, a sociedade de comunicação e de consumo desenvolve uma lógica da moda que se estende para o corpo social, através de imagens que apelam invariavelmente para a figura do indivíduo "sempre mais jovem" (top models em faixas de idade cada vez menores), "leve, fugaz, despreocupado e feliz". A força das significações imaginárias sociais da juventude se denota no fato de todos se sentirem impelidos a permanecer jovem o mais tempo possível, sob fortes ameaças de estigmas de degradação humana produzida pelo tempo, tanto no corpo e na sexualidade como na inteligência.

O ensaio "A juventude como sintoma da cultura" (Kehl, 2004) aborda exemplarmente essa inversão identificatória. A questão, aqui, não é indagar se antes era melhor ou agora se está inaugurando um novo tempo danoso ou mais benéfico; trata-se, antes de tudo, apontar para o efeito paradoxal desse processo na condição jovem. O problema se encontra justamente neste ponto: quanto mais os jovens se tornam alvos do mercado de consumo, menores são as chances de se tornar consumidor (o acesso ao consumo passa invariavelmente pelo mercado de trabalho, para a grande maioria). Quanto mais a juventude se torna símbolo de vitalidade, beleza, capacidade inventiva, bem como de outros quesitos da excelência humana, via imagens da indústria cultural, menos eles sentem ter chances de sê-lo na realidade concreta de sua existência. Os jovens sentem que estão "mais inteligentes do que os seus pais", eles obtêm uma média maior de tempo de escolaridade do que seus pais (houve elevação no investimento de capital humano) e, ainda por cima, dominam melhor a ferramenta tecno-informática possibilitandolhes, a princípio, rapidamente uma maior abertura cognitiva e relacional, porém isso tudo não lhes assegura tranquilidade relativa ao futuro.

Na pista interpretativa de Kehl (2004), quando os jovens estão alçados ao patamar de referência para "todas as idades" eles se tornam modelos inalcançáveis para si mesmos na medida em que as condições objetivas de produção da vida caminham no sentido inverso para eles. Isso, para a autora, só vem contribuir para um aumento exponencial da violência, visto que os jovens sentem a inclusão ser apenas uma representação imagética, isto é, no limite da realidade concreta de sua existência social a possibilidade de consumo é mínima ou nula. Ora, muitos jovens, na sociedade brasileira, estão excluídos do processo de aquisição de competências necessárias à entrada no mercado de trabalho. $\mathrm{O}$ modelo de inclusão social passa invariavelmente, na sociedade contemporânea, pela educação e trabalho. Mas não há educação e emprego para todos!

A crise econômica, apesar de estar visivelmente instalada na zona do euro, não está só nela circunscrita. Segundo as projeções do FMI e do Banco Mundial, a crise da dívida pública generalizase no mundo provocando a desaceleração da economia mundial, em 2012 (Le Monde, 2012). A grande onda de desemprego na zona do euro, já vem atingindo fortemente a população jovem em início de sua vida ativa no mercado de trabalho. Há tentativas de inserção profissional e social, por parte de jovens europeus, em outros continentes. Por exemplo, dados da Coordenação geral de imigração do Ministério do Trabalho e do Emprego (2012), apontam que, no Brasil, a imigração de jovens estrangeiros e provenientes, principalmente da Europa, duplicou no Brasil: “o número de estrangeiros regulares no país aumentou em 50\% de dezembro de 2009 para julho de 2011 - de 961 mil para 1,46 milhão, segundo dados do Ministério da Justiça. Os vistos têm sido emitidos para realização de trabalhos temporários, estudos e pesquisas".

Têm-se, de uma parte, jovens com sensação de que quanto mais estudam, menores são suas chances de obter um lugar profissional que corresponda minimamente aos anos dedicados a estudos. Esses que se encontram no lado social da "inclusão", que puderam ter uma trajetória escolar até o ensino superior, com todos os suportes - familiar e institucional -, veem-se perplexos e se perguntando: de que adiantou tantos anos de estudos e esforços, obtendo inclusive bons conceitos escolares, se no final desse trajeto não há para onde ir? Obter um lugar profissional não parece ser evidente. Aumentaram os seus conhecimentos/ saberes ou capital cultural, comparados com seus pais; porém, na mesma medida, viram diminuídas as chances para o exercício das habilidades adquiridas e, consequentemente, com menos chances de cavar uma existência “digna”. O que Gaulejac (1994) observava, a partir de pesquisas focadas na França na década de 1990, em termos de luta por posições em lugar de luta de classes, continua atual.

De outra parte, há aqueles jovens que não puderam contar com suportes familiares e institucionais, após terem concluído seus estudos superiores, não sem inúmeras dificuldades, e devem se contentar com "trabalhos menores" ("para que serviu então o diploma superior?”). Há, ainda, outra parcela (aliás, no Brasil, majoritária) que, desde cedo, não podendo contar com tais suportes e tendo que interromper estudos para se contentar com trabalhos "menores ainda", vê-se sempre na iminência de ser lançada para a via da "marginalização" e da vulnerabilidade sociopsicológica.

Se podemos, de um lado, identificar hoje uma "periferia"6 de jovens que se movem, , ativamente, bem mais que na década 
anterior, para encontrar caminhos inventivos de inclusão e/ ou de participação social e política, através de redes sociais e outras atividades alternativas; podemos, por outro, identificar processos de transição para caminhos do "fora da norma" onde determinados jovens passam a ser potenciais "frequentadores das prisões". Estas se lotam a cada dia, com indivíduos de faixas etárias mais baixas, se comparadas com décadas anteriores, segundo Wacquant (2001) que, em seu estudo sobre política de encarceramento em massa nos Estados Unidos e na Europa, também se volta para referenciar o caso brasileiro ${ }^{7}$. Diante de estatísticas "alarmantes" e fatos que se evidenciam no cotidiano urbano das grandes cidades, as sociedades ocidentais parecem adquirir a certeza de que há que se adotar medidas urgentes contra essa população cada vez mais jovem enveredando pelos caminhos da "delinquência".

\section{$A$ vontade de punir ${ }^{8}$}

Como desdobramento dessa certeza social quanto à violência juvenil, tem-se todo um processo discursivo que hoje assistimos em torno da questão da redução da maioridade penal, em algumas sociedades contemporâneas. Tomemos como referência o que ocorre no Brasil. É notória a discussão presente, em vários espaços sociais: no Congresso, nas ruas, nos canteiros de construção civil, nos transportes coletivos, nos pontos de táxi, nos salões de beleza, nos points de lazer onde frequentam jovens das camadas médias e mais abastadas das cidades ou nos diversos sites da internet, sejam fóruns de discussão, sejam espaços de edição de textos de jornalistas, de "especialistas da juventude" (psicólogos, psiquiatras, educadores, religiosos, advogados etc.) e de "não-especialistas" (simplesmente os cidadãos "preocupados" com a violência). Enfim, todos falam, opinam e se posicionam, "pelo sim ou pelo não", sobre a questão da redução da maioridade penal.

Em outubro/2011, foi divulgada a pesquisa, realizada pelo IBOPE em 140 municípios brasileiros, Retratos da sociedade brasileira: segurança pública, sob o patrocínio e edição da Confederação Nacional da Indústria (CNI), para revelar, dentre os diversos resultados relacionados à segurança pública no Brasil, que não somente "a grande maioria dos entrevistados defende a redução da maioridade penal para 16 anos", como ela anseia pelo endurecimento da pena. Esse relatório é parte do processo discursivo que se intensifica gradativamente nos diversos espaços sociais da sociedade brasileira.

Igualmente, em janeiro/2011, foi divulgado o resultado de uma enquete no Congresso sobre a Proposta de Emenda Constitucional que reduz a maioridade penal: pelo menos $45 \%$ dos deputados da nova legislatura estavam a favor da realização de plebiscito sobre a redução da maioridade penal. Diversos projetos de lei $i^{9}$ tramitam na Câmara Federal e no Senado visando reduzir a idade penal, há mais de uma década; dentre esses, alguns defendem a redução para os 12 anos. ${ }^{10}$

Esse panorama discursivo, ainda que incompleto, esboça aquilo que chamamos de vontade de punir na sociedade atual. A nossa hipótese é que essa vontade de punir os jovens está associada a dois processos que se articulam entre si: $1^{\underline{0}}$ ) passagem do Estado-Providência para o Estado Penal; $2^{\underline{\underline{o}}}$ ) política global da sociedade de controle.
O primeiro - relativo à passagem do Estado-Providência para o Estado Penal - tem como significação maior a migração de interesses e recursos, antes destinados à assistência, para o custeio do sistema carcerário e policial (Alvarez, 2007; Wacquant, 1998, 2001a, 2001b). Trata-se de uma tendência mais ampla nas sociedades contemporâneas que, em certos países, aparece com maior nitidez, conforme observam os autores. Notam que teria havido processos profundos de recomposição no tratamento do crime e dos criminosos, iniciados a partir de meados da década de 1970. Aliás, a doutrina da "tolerância zero" norte-americana, que se expande na América Latina, resulta de todo um desmantelamento das políticas de assistência social aos mais pobres (Wacquant, 2001). Daí a intensificação da ação policial e das sanções penais, visando agora todos os atos transgressivos, até mesmo a menor incivilidade.

O maior agravante, nesse contexto, é o princípio da suspeição que passa a permear a sociedade como um todo. Ora, nas grandes cidades pulula a diversidade: presença de estranhosestrangeiros dos mais diversos tipos, de uma variedade de biótipos à multiplicidade de características psicológicas, culturais e sociais. Nelas, certos tipos passam a ser alvos imediatos de suspeita, bastando existir como tal ou qual, isto é, bastando ser portador de algum estigma social. A recepção de tal "doutrina" no Brasil tem sido ampla, tanto nos meios institucionais de segurança pública quanto na sociedade como um todo, e se tornou objeto de enaltecimento devido à sua suposta eficácia.

\section{Sociedade de controle e paradoxos}

O segundo processo social, em estreita conexão com a vontade de punir, está associado à política global da sociedade de controle. O importante a se observar, aqui, é que não se trata de um mero dispositivo de aperfeiçoamento de técnicas de policiamento; porém, de uma medida que participa daquilo que Foucault (1995) observava, qual seja, da totalização das estruturas de poder moderno que nos repõe num regime de poder onde se exerce a biopolítica como uma política totalitária ${ }^{11}$. Agamben (2004), ao radicalizar a tese de Foucault, propõe-nos a pensar a totalidade da sociedade contemporânea tornando-se um campo (referência ao "campo de concentração"). Nessa sua obra, no capítulo intitulado O campo como nómos do moderno (p. 172-186), contrariamente a uma definição convencional que considera o campo o local onde se realizou a mais conditio inhumana praticada na face da terra, Agamben sugere que o vejamos como a matriz oculta que governa o espaço político no qual vivemos nos dias de hoje.

O sistema político não ordena mais formas de vida e normas jurídicas em um espaço determinado, mas contém em seu interior uma localização deslocante que o excede, na qual toda forma de vida e toda norma podem virtualmente ser capturadas. O campo como localização deslocante é a matriz oculta da política em que ainda vivemos... (p.182).

Tomando por referência as abordagens acima é que propomos olhar a vontade de punir jovens e adolescentes como algo que se inscreve no quadro de uma política totalizante da sociedade brasileira que, por sua vez, está inserida na política global da sociedade de controle. Num breve texto, Deleuze (1992b) define o que por isso pode-se entender. Trata-se de 
uma sociedade caracterizada pela presença de novas formas de controle e de poder onde se ampliam as tecnologias políticas modernas, tão bem analisadas por Michel Foucault sob a denominação de sociedade disciplinar e biopolítica. Novas formas que viriam escancarar facetas inéditas que constituem alguns paradoxos da sociedade contemporânea ${ }^{12}$.

Deleuze enfatiza a problemática da subjetivação contemporânea ou das modulações subjetivas face às novas formas de controle social e subjetivo. Note-se que o grande paradigma atual de funcionamento das sociedades são as tecnologias informacionais e comunicacionais que operam no âmago da subjetividade humana. Controle contínuo e permanente que se faz por via da comunicação instantânea modulando fluxos sociais, inclusive os fluxos do desejo (Deleuze, 1992b). Deslocamento das relações de poder para as quais o campo virtual ganha primazia; mas também reestruturação das antigas formas disciplinadoras. Da moldagem fixa da sociedade disciplinar passa-se, na sociedade de controle, observa o autor, a um tipo de funcionamento que se dá por meio de redes flexiveis, moduláveis. Controle ao ar livre (Virilio, 1977) e outras velocidades: atendimento de enfermos a domicílio, educação à distância e meios virtuais, atividades profissionais executadas fora do espaço convencional de trabalho (na empresa ou na fábrica - em direção ao empreendedorismo individual), monitoramento de atividades ou de locais de serviço (a exemplo de escolas infantis com monitoramento, através de câmeras em que os pais podem observar ou vigiar, a qualquer momento, de casa ou do trabalho, atividades e comportamentos dos seus filhos). Pode-se pensar em seguranças, proteção e maior grau de liberdade nessas diversas situações em que doentes, usuários, alunos, filhos, trabalhadores e empregados se libertam das "garras e olhos" vigilantes dos controladores presenciais; porém, deve-se pensar, também, em novas formas de controle (sobretudo, as de ordem virtual) que se desenvolvem a partir dessas novas situações.

Hardt e Negri (2004) abordam esse fenômeno, na esteira de M. Foucault e G. Deleuze, tendo por parâmetro o mundo do trabalho pós-fordista (a dinâmica real de produção na sociedade biopolítica) e identificam "mecanismos de comando cada vez mais "democráticos" e cada vez mais imanentes ao campo social, distribuídos por corpos e cérebros dos cidadãos" (p. 42). O paradoxo do poder (p. 44) é, por eles, denominado paradoxo da pluralidade e da multiplicidade: de um lado, haveria absorção da sociedade pelo poder; de outro, a explosão na sociedade civil daquilo que era previamente coordenado ou mediado pelo poder ou pelo Estado. As resistências não são mais operantes nas margens do sistema social, do mesmo modo que o poder não se encontra unicentrado em algum ponto fixo. Admitese, nessa perspectiva teórica, a existência de um potencial de insubordinação e revolta, ao mesmo tempo em que o poder reforça seus mecanismos e dispositivos de controle e pressão. Paradoxo, explicam eles, porque à medida que o poder envolve todos os elementos da vida social, haveria igualmente a perda de sua capacidade na mediação de diferentes forças sociais, podendo, nesse momento, emergir contextos ou ambientes de acontecimentos com efeitos inesperados. Processo recursivo: o poder renova seus mecanismos de controle à medida que as liberdades se expressam e saem do seu controle.
Vide o ACTA - Anti-Counterfeiting Trade Agreement (Acordo Comercial Antifalsificação), um acordo de comércio que está sendo firmado por 31 nações, tendo à frente os Estados Unidos e que tem por objetivo padronizar, nos vários países que participam desse Tratado, a legislação da propriedade intelectual e direitos autorais na internet. Se, de um lado, advoga-se a proteção de direitos, de outro, entende-se que se trata de um cerco que constrange a circulação de informações na medida em que o acordo propõe intervenção nas comunicações pessoais, como também interceptação de correspondências. Vigiar e punir está na ordem do dia, pelo estabelecimento de novos tipos de infração: provedores de acesso e hospedagem na internet passam a ter papel de vigilantes na troca de conteúdos, podendo realizar intervenções sem ordem judicial; trocas não-comerciais de arquivos, via internet, passam a ser crime.

Observando as denúncias proferidas por determinados órgãos da imprensa, a exemplo do dossiê ACTA (Diplô: 2010), diríamos que estamos assistindo àquilo que Deleuze e Guattari (1995, 1996a, 1996b, 1997a, 1997b) analisam em Mil Platôs, qual seja, a tentativa de captura da potência de vida. Interessante, porém, notar o que os autores ponderam quanto à outra face desse processo: que a vida se intensificaria na medida em que as conexões se constituem por meio de redes (rizoma). Pressupõese que a solidariedade e relações colaborativas possam se desenvolver muito mais, cotidianamente, através dos recursos propiciados pela internet, sendo a população jovem a que mais acessa essa nova via de interação. Não se está aqui argumentando que a internet "cria a potência de vida", mas sim que ela é um suporte importante, nos dias de hoje, para conectar criatividades em germinação e que, muitas vezes, se encontram desconectadas umas das outras, isto é, localizadas e isoladas. Assim, ACTA e diversos projetos de leis em curso vão se "tornando necessários", a fim de interceptar não só as interações como também colocar limites a toda possibilidade de novas inventividades humanas autônomas que ameacem o poder, a exemplo do Médio Oriente onde ocorreram as "intifadas" e as "primaveras da praça Tahir". O fechamento do Megaupload ${ }^{13}$ em janeiro/2012 não seria mais uma tentativa de cerceamento do acesso ao conhecimento mais amplo que inspira multidões a pensar mais autonomamente?

Foucault já advertia, em sua microfísica do poder, que as práticas de liberdade são a condição própria da existência do poder. Se o ACTA está sendo planejado com impactos imediatos nas interações humanas, há, ao mesmo tempo, insurgências que irrompem até em lugares inéditos. Em diversas partes do mundo, articulações são gestadas nos diversos espaços da sociedade civil. Há, no Twitter, Facebook e outras redes sociais online, intensa postagem com importantes referências ao material sobre o acordo: blogs e endereços de sites para quem quiser saber mais detalhes sobre os avanços desse acordo e os pontos de rede de "resistência" que se formam em algumas partes do mundo.

Ao desenvolvermos esses aspectos do paradoxo da pluralidade e da multiplicidade, estamos trazendo alguns fatos que mostram que os jovens não estão vivendo no "melhor mundo possível", porém, este mundo é mais aberto do que se pode imaginar, a fim de torná-lo quiçá melhor; quiçá ainda pior. Sem dúvida, de uma parte, há medidas de austeridade econômica de tempos difíceis, impostas a certos países em busca de salvação de 
sua economia (por exemplo, aquelas que se encontram na zona do euro), não sem reflexos sobre economias de outros países; expansão da categoria de desempregados; sensação de liberdade desbaratada pela falta de linguagem "para articular nossa falta de liberdade", como diz Zizek (2011a); e intensificação do esgotamento da dimensão da experiência e de sua transmissão (conforme perspectiva de Benjamin, 1985).

De outra, há uma pluralidade de ações/atitudes coletivas que ganham expressão, a cada dia, em vários cantos do planeta, quase sempre com ar improvisado e intempestivo, servindo-se dos meios de comunicação mais atuais para dar visibilidade a atos de protesto ao establishment. Alguns deles mais localizados e com um escopo de ações pontuais; outros com potencial de alastramento maior. Na maior parte desses atos, comparecem jovens insatisfeitos, em seu modo de existir na sua própria sociedade, abstração feita quanto à sua pertença social.

Entretanto, não se trata apenas desses atos políticos que ganharam maior cobertura da mídia, como Occupy Wall Street em Nova York, Puerta del Sol em Madri ou Praça Tahir no Egito, dentre alguns exemplos que podemos pinçar dos acontecimentos recentes; há, também, aqueles atos culturais e artísticos, de caráter coletivo, que aos poucos vão se arrojando em propostas políticas, como certos grupos de hip hop que buscam uma atuação localizada (numa "quebrada", como diriam certos rappers ativistas) não sem preocupações de ordem global.

Enfim, na massa global, se a juventude vive intensamente tais paradoxos societais, ela tanto vive a experiência de se ver barrada em suas potencialidades como vive experiências de revolta, indignação e engajamento ${ }^{14}$. Suas respostas são, por vezes, inventivas, e denotam o desejo de mudança social. E, por outras, elas extravasam caoticamente até fazer vítimas; a sociedade disso padece e os jovens, mais ainda.

\section{Processos inventivos de experimentação coletiva}

Nesta parte final do texto, vamos insistir um pouco mais na positividade de determinadas experiências sociais. Basta uma breve pesquisa, na internet, para nos depararmos com a profusão de grupos e coletivos jovens e suas propostas nos campos artísticos e culturais, por exemplo. Ao analisar algumas das propostas de grupos, que têm se expressado nesses campos, vemos que elas não se reduzem às questões musicais ou artísticas. Elas encerram, no conjunto de seus atos, uma potencialidade inventiva do político, enquanto uma nova postura de vida face aos problemas vivenciados pelos jovens em determinados espaços sociais ${ }^{15}$.

Nossa própria pesquisa ${ }^{16}$ tem por foco os jovens da "periferia" e suas inventividades micropolíticas (Deleuze \& Guattari, 1995, 1996a, 1996b, 1997a, 1997b) em face da vida adversa numa sociedade na qual são insidiosas e insistentes as relações de desigualdade social. Sua principal característica é o desenvolvimento de pesquisa-intervenção, através de dois eixos fundamentais estreitamente articulados: de um lado, um eixo de pesquisa fundamental com análise centrada em "espaços periféricos" onde emergem experiências juvenis a partir de atividades culturais e artísticas (atualmente, tem-se centrado análise sobre grupo de jovens engajados em um movimento cultural hip hop); de outro, o eixo de intervenção sociológica através de projetos de extensão universitária. Mais especificamente, a pesquisa está relacionada às produções realizadas por coletivos do hip hop e seu engajamento na produção artístico-cultural e política com efeitos na subjetividade dos jovens. Através daquilo que os agitadores culturais chamam de "movimento hip hop", determinados grupamentos juvenis intentam inventar uma nova postura de vida, face aos problemas vivenciados nas "periferias" urbanas ${ }^{17}$. Isto é, jovens de determinados segmentos econômicos inferiores da sociedade "descobriram" na arte um veio de produção de uma nova subjetividade que vem fazer face aos paradoxos que a sociedade lhes impõe. Tratamos, assim, da emergência das minorias sociais juvenis e de suas potencialidades. Entendemos por minoria social aqueles grupos ou coletivos que se orientam para um devir-minoritário, que, por sua vez, é entendido como uma saída das redundâncias dominantes (Guattari \& Rolnik, 1985). Os jovens ativistas do hip hop almejam um devir-minoritário na medida em que intentam abrir "brechas" para a produção de uma subjetividade não mais capturada pelo princípio do desvalor humano. Não nos preocupamos se configuram novos movimentos sociais com uma dada identidade e com algum tipo de possibilidade de construção de uma agenda comum entre a juventude, latino-americana ou outra. Nossa despreocupação em relação à perspectiva identitária avizinha-se da conclusão que chegam os organizadores da obra Jovens em Sudamerica (Novaes \& Santoro, 2008):

A visão culturalista de identidade como 'comunidade de valores' não é útil para pensar os processos em curso de construção de identidade juvenil. Por outro lado, é preciso também afastar a ideia de identidade única, exclusiva, pronta para manifestar um encoberto e consistente ethos juvenil. Tal como sugere Canclini, estamos falando de identidades que se constroem em processos de enfrentamento, oposição, dominação, submissão e resistência que ocorrem no plano simbólico e material das relações sociais. Ou seja, passam pela articulação de elementos subjetivos e variadas situações objetivas (p. 200-1).

Podemos talvez ampliar, ainda mais, essa sugestão baseada em Canclini e pensar com Deleuze, desgarrando-nos da ideia de construção identitária para refletir em termos de devir jovem, como algo que se orienta para novas modalidades de organização da subjetividade coletiva. Deleuze repõe a problemática da subjetividade, pondo em jogo uma teoria, inspirado em Spinoza, que aborda não o nível do sujeito-indivíduo, ou seja, das identidades, mas sim a vida, a potência da vida. Toca-se, aqui, o plano das vivências concretas - a pragmática social com incidência na subjetividade do jovem que passa a lidar de maneira diferente com o princípio de realidade. Isto é, o plano das experiências, as quais se encontram conectadas com processos inventivos de experimentação coletiva, numa ideia micropolítica, e fora das raias do trabalho ativo e produtivo ou às margens da dinâmica da produção.

Pela experiência de desterritorialização que a arte parece permitir, certos jovens mostram que aprendem "na marra" a inventar alternativas para a sua vida. Podemos comprovar a sensível mudança no modo como determinados jovens passaram a viver, na e pela periferia, a partir do momento que realizaram experimentações artísticas ${ }^{18}$. Podemos dizer isso pela nossa 
própria pesquisa, se compararmos com o que vivenciamos há 15 anos, quando iniciamos nossas incursões, como pesquisadores, no universo de jovens adolescentes de áreas pobres, na cidade do Natal-RN, Brasil. Temos acompanhado movimentações e atuações de jovens engajados em ações artístico-culturais, com ressonâncias políticas, e gradativamente temos descoberto novos estratos de potencialidade inventiva de formas de viver. Isso nos leva a formular que o eixo artístico-cultural constitui-se em um importante recurso simbólico para jovens que contam com poucos suportes na sociedade em que vivem. Na junção da arte e política, determinados jovens passam a pensar e arquitetar a resistência social ${ }^{19}$.

Resta dizer que, para nós, a caixa de ferramentas nocional e conceitual, que se encontra no interior dos 5 (cinco) volumes de Mil platôs (Deleuze \& Guattari, 1995, 1996a, 1996b, 1997a, 1997b) permite-nos aprofundar a compreensão de certas dinâmicas emergentes que têm os jovens por principais protagonistas, hoje, em determinados espaços da sociedade brasileira e em outros países latino americanos. Deleuze (1992a), o filósofo do Elogio ao movimento, nos é caro, especialmente na sua abordagem das produções criativas, produções de valores, relações sociais, afetos, formações. Desde o início dos anos 1980, ele e seu parceiro Guattari se dedicaram a ler "os fenômenos emergentes das formas marginais do trabalho inconformado... para ressaltar que a produção da riqueza e a exploração extrapolavam as fábricas e investiam na sociedade em seu conjunto, como um devir-minoritário" (Negri, 2001, p. 32).

Com eles, pensamos o devir que brota dos fluxos de intensidade vital. Assim, vida e pensamento não estão desgarrados, mas bem relacionados enquanto um problema eminentemente micropolítico, e como um exercício de pragmática. Ora, pensar e viver apelam para inventividades. Finalizamos o texto com uma frase de Deleuze (1992a, p. 218) que anima a nossa pesquisa e os jovens com quem trabalhamos: "acreditar no mundo significa principalmente suscitar acontecimentos, mesmo pequenos, que escapem ao controle, ou engendrar novos espaços-tempos, mesmo de superfície ou volume reduzidos".

\section{Referências}

Agamben, G. (2004). Homo sacer: o poder soberano e a vida nua I. Belo Horizonte: UFMG.

Alvarez, M. C. (2007). Punição, sociedade e história: algumas reflexões. MÉTIS: História \& Cultura, 6(11), 93-105.

Benjamin, W. (1985). O narrador. Considerações sobre a obra de Nikolai Leskov. In Magia e técnica, arte e política. Ensaios sobre literatura e história da cultura, Obras Escolhidas (vol. 1). São Paulo: Brasiliense.

Biblioteca Diplô (2010). Dossiê ACTA: para desvendar a ameaça ao conhecimento livre. Recuperado de http://diplo.org.br

CNI-IBOPE (2011). Retratos da sociedade brasileira: segurança pública. Brasília: CNI. Recuperado de http://www.cni.org.br

Deleuze, G. (1992a). Conversações. Rio de Janeiro: Editora 34.

Deleuze, G. (1992b). Post-scriptum sobre as sociedades de controle. In G. Deleuze (Org.), Conversações (pp.219-226). Rio de Janeiro: Editora 34.

Deleuze, G., \& Guattari, F. (1995). Mil Platôs: capitalismo e esquizofrenia (Vol. 2). Rio de Janeiro: Editora 34

Deleuze, G., \& Guattari, F. (1996a). Mil Platôs: capitalismo e esquizofrenia
(Vol.1). Rio de Janeiro: Editora 34.

Deleuze, G., \& Guattari, F. (1996b). Mil Platôs: capitalismo e esquizofrenia (Vol. 3). Rio de Janeiro: Editora 34.

Deleuze, G., \& Guattari, F. (1997a). Mil Platôs: capitalismo e esquizofrenia (Vol. 4). Rio de Janeiro: Editora 34.

Deleuze, G., \& Guattari, F. (1997b). Mil Platôs: capitalismo e esquizofrenia (Vol. 5). Rio de Janeiro: Editora 34.

Foucault, M. (1977). História da Sexualidade I. A Vontade de Saber. Rio de Janeiro: Graal.

Foucault, M. (1984). L'éthique du souci de soi comme pratique de la liberté. In Dits et Écrits II, 1976-1988. Paris: Éditions Gallimard.

Foucault, M. (1990). O uso dos prazeres. Rio de Janeiro: Graal.

Foucault, M. (1995). O sujeito e o poder. In H. Dreyfus \& P. Rabinow (Orgs), Michel Foucault - uma trajetória filosófica: para além do estruturalismo e da hermenêutica (pp.231-249). Rio de Janeiro: Forense Universitária.

Foucault, M. (2001). Une esthétique de l'existence. In Dits et Écrits II, 1976-1988. Paris: Éditions Gallimard.

Foucault, M. (2006a). Poder e saber. In Ditos e Escritos. Vol. IV. Rio de Janeiro: Ed. Forense Universitária.

Foucault, M. (2006b). A hermenêutica do sujeito. Curso dado no Collège de France (1981-1982). São Paulo: Martins Fontes.

Foucault, M. (2008). Nascimento da Biopolítica. Curso dado no Collège de France (1978-1979). São Paulo: Martins Fontes.

Gaulejac, V. (1994). De l'excellence à l'exclusion. In V. de. Gaulejac \& I. T. Léonetti (Orgs.), La lutte des places (pp. 39-49). Paris: Hommes et Perspectives.

Guattari, F., \& Rolnik, S. (1985). Micropolitica - cartografias do desejo. Petrópolis: Vozes.

Hardt, M., \& Negri, A. (2004). Produção Biopolítica. In M. Hardt \& A. Negri (Orgs), Império (pp. 185-215). Rio de Janeiro: Editora Record.

Hessel, S. (2010). Indignez-vous! Montpellier: Indigène Editions.

Hessel, S. (2011). Engagez-vous! La Tour d'Aigues: Editions de l'Aube.

Kehl, M. R. (2004). A juventude como sintoma de cultura. In R. Novaes \& P. Vannuchi (Orgs.), Juventude e sociedade: trabalho, educação, cultura e participação (pp. 89-114). Rio de Janeiro: Editora Fundação Perseu Abramo.

Lazaratto, M. (2000). Du biopouvoir à la biopolitique. Majeure: biopolitique et biopouvoir. Recuperado de http://multitudes.samizdat.net/Du-biopouvoira-la-biopolitique

Le Monde France (2012). La Banque mondiale prévoit um ralentissement de l'économie mondiale em 2012. Recuperado de http://www.lemonde.fr/ crise-financiere/article/2012/01/18/la-banque-mondiale-un-ralentissementde-1-economie-en-2012_1630955_1581613.html

Lipovetsky, G. (2010). A felicidade paradoxal. São Paulo: Companhia das Letras. Negri, A. (2001). Exílio - seguido de valor e afeto. São Paulo: Iluminuras.

Novaes, R., \& Ribeiro, E. (2010). Livro das Juventudes Sul-americanas. Rio de Janeiro: IBASE. Recuperado de http://www.ibase.br/pt/biblioteca-2/

Novaes, R., \& Santoro, M. (2008). Ser jovem na América do Sul: Um epílogo. In Ser Joven en Sudamérica. Diálogos para la construcción de la democracia regional (pp. 181-210). Santiago: Productora Gráfica Andros.

Sposito, M. P. (Coord.) (2009). O Estado da Arte sobre juventude na pósgraduação brasileira: Educação, Ciências Sociais e Serviço Social 19992006. Belo Horizonte: Argvmentvm.

Takeuti, N. M. (2008). Saberes em construção: coletivo jovem em formação na sua resistência social. In M. da C. Passeggi \& E. C. Souza (Orgs.), (Auto)Biografia: formação, territórios e saberes (pp. 203-221). São Paulo: PAULUS.

Takeuti, N. M. (2009). Movimentos culturais juvenis nas "periferias" e inventividades sociais. In P. H. Martins \& R. de S. Medeiros (Orgs.), América Latina e Brasil em perspectiva (pp. 331-350). Recife: Ed. Universitária da UFPE.

Takeuti, N. M. (2010). Refazendo a margem pela arte e política. Revista Nómadas Bogotá, 32, 13-25. 
Takeuti, N. M., \& Bezerra, M. A. (2009). Trajetórias de um coletivo jovem: nem só de prática-Gramática da Ira. In N. M. Takeuti \& C. Niewiadomski (Orgs.), Reinvenções do sujeito social - teorias e práticas biográficas (pp. 105-125). Porto Alegre: Sulinas.

Virilio, P. (1977). Vitesse et Politique: essai de dromologie. Paris: Éditions Galillée.

Wacquant, L. (1998). L'Ascension de l'État pénal en Amérique. Actes de la Recherche en Sciences Sociales, 124, 7-26.
Wacquant, L. (2001a). As prisões da miséria. Rio de Janeiro: Jorge Zahar Ed.

Wacquant, L. (2001b). Punir os pobres. A nova gestão da miséria nos Estados Unidos. Rio de Janeiro: Freitas Bastos, col. Pensamento Criminológico.

Zizek, S. (2011a). A tinta vermelha: discurso de Slavoj Zizek aos manifestantes do movimento Occupy Wall Street. Recuperado de http://boitempoeditorial. wordpress.com/2011/10/11/a-tinta-vermelha-discurso-de-slavoj-zizek-aosmanifestantes-do-movimento-occupy-wall-street/

Zizek, S. (2011b). O horizonte está aberto. Recuperado de www.outraspalavras.net

1. Evento explicitado no editorial deste Dossiê

2. Foge ao propósito deste artigo relacionar os diversos estudos e pesquisas atualmente disponíveis; alguns desses serão indicados, no decorrer do texto.

3. Tais como: Comissão Econômica para a América Latina e o Caribe (CEPAL), Organização Ibero-Americana da Juventude (OIJ), Programa das Nações Unidas para o Desenvolvimento (PNUD), Organização das Nações Unidas para a Educação, a Ciência e a Cultura (UNESCO) entre outras.

4. Nas referências disponibilizamos o site para acessar informações adicionais.

5. Importante mencionarmos, entre outros, Sposito (2009).

6. Colocamos esse termo entre aspas, pois, ele se refere a um conceito produzido pelos próprios jovens, conforme esclarecido em Takeuti (2009).

7. Vide sua Nota aos leitores brasileiros - Rumo a uma ditadura sobre os pobres? (pp. 7-15) na obra As prisões da miséria (2001).

8. A ressonância das ideias contidas na obra A vontade de saber (Foucault, 1977) encontra-se condensada nos termos "a vontade de punir". Wacquant (1998, 2001a, 2001b) aborda a questão da penalização da pobreza.

9. A partir da Proposta de Emenda à Constituição (PEC) 171/93, proposta pelo Deputado Benedito Domingos (PP-DF), mais outras 29 desde então (Campos, 2006).

10. PEC N ${ }^{0} .345$ de 06/12/2004 de autoria de Silas Brasileiro (PMDB-MG).

11. Desdobramentos da noção de biopolítica foram feitos entre outros por Hardt e Negri(2004).

12. Outros autores nutrem esta parte da discussão: Hardt e Negri, 2004; Lazaratto (março/2000); entre outros.

13. Megaupload, um site de compartilhamento (em 18 línguas diferentes) de arquivos (imagens, vídeos e filmes). O site saiu do ar recentemente (19/01/2012) e seu fundador preso juntamente com demais membros executivos da empresa, sob acusações de compartilhar arquivos de mídia protegidos por direitos autorais.

14. A propósito, os livros Indignez-vous! (2010) e Engagez-vous! (2011) de S. Hessel tiveram eco não só junto à intelligentzia francesa, como também em vários outros espaços sociais na França.

15. Consultar Takeuti (2008, 2009, 2010) e Takeuti e Bezerra (2009).

16. Desenvolvida no interior do Grupo de Estudos Cultura e Subjetividades - Poiesis, o qual possui uma linha de pesquisa intitulada A micropolítica dos jovens em ações coletivas - Inventividades e subjetividades. Atualmente, desenvolve-se no âmbito do PROEXT 2012-MEC o Programa Germinal - Construção coletiva por um programa de desenvolvimento comunitário sustentável.

17. Remetemos a Zizek (2011b) para comentários relacionados que contribuem para a discussão.

18. Mais uma vez, remetemos a Takeuti (2008; 2009; 2010) e Takeuti \& Bezerra (2009).

19. Conforme detalhes de discussões em artigo precedente (Takeuti, 2010).

Norma Missae Takeuti, pós-doutora pela UFR Sciences Sociales/Laboratoire de Changement Social da Universidade Paris 7, é Professora Associada 3 da Universidade Federal do Rio Grande do Norte (UFRN). Endereço para correspondência: Universidade Federal do Rio Grande do Norte, Centro de Ciências Humanas Letras e Artes, Departamento de Ciências Sociais. Campus Universitário Lagoa Nova. CEP: 59072-970. Natal, RN. E-mail: nortak@uol.com.br 